\title{
REDES EMERGENTES DE DISTRIBUIÇÃO CERÂMICA NO MEDITERRÂNEO ANTIGO: AS LUCERNAS DE TERRA SIGILLATA DA ÁFRICA PROCONSULAR
}

Marcio Teixeira-Bastos ${ }^{1}$

\begin{abstract}
Resumo
O presente artigo examina o beneficio da utilização da Ciência das Redes, do pensamento sobre redes, e das metodologias e técnicas analíticas aplicadas ao estudo da Arqueologia e História Antiga, com especial foco para a economia romana, produção de cerâmica, e a representatividade étnico-religiosa na materialidade. As recentes aplicações das técnicas e análises de redes em Antiguidade Clássica e Arqueologia, demonstram que existe uma variedade de abordagens que permite reconhecer padrões e pensar sobre os fenômenos (humanos e não-humanos) como produtos dos processos em rede. A conectividade provincial é um dos aspectos mais debatidos em economia romana e tem o potencial de permitir abordagens de grupos (clusters), nesse caso religiosos, através de suas materialidades em redes de contato e consumo, com extroversões na macro-economia romana. Os padrões de consumo de cerâmica no interior e nas regiões costeiras da África Proconsular demostraram ser muito diferentes. A tendência dominante de voltar-se para as comunidades formadas e estruturadas em torno de identidades nativas, especialmente aquelas assentadas nos principais centros urbanos e áreas maiores, parece se estabelecer como um argumento sólido para as negociações na economia do Império Romano. A África Proconsular demonstra evidências que as oficinas cerâmicas através de suas áreas produtores e redes emergentes, estabeleceram-se procurando tanto engajar-se nos amplos negócios do Mediterrâneo Antigo, quanto atender tanto a demanda religiosa de consumo.
\end{abstract}

\section{Palavras-chave}

Ciência das Redes; Arqueologia das Redes; Antiguidade Clássica; África Proconsular.

\footnotetext{
${ }^{1}$ Pós-doutorando - Universidade Estadual Paulista, Assis, Brasil. Visiting Scholar at Stanford University, Archaeology Center, School of Humanities \& Sciences.

https://archaeology.stanford.edu/people/marcio-teixeira-bastos

E-mail: márcio_quisleu@yahoo.com.br
} 


\begin{abstract}
This paper surveys the use of Network Science, especially the role of Archaeological Networks to the study of Archeology and Ancient History. Network thinking and network science are valuable methodologies and analytical techniques to apply to the study clay lamps in the framework of Roman economy. The recent application of network analysis in Antiquity and Archaeology has demonstrated that there are a variety of approaches to recognizing network patterns or thinking about phenomena as products of networked processes. Provincial connectivity is one of the most debated aspects of Roman economics, and ceramic consumption patterns in the interior and coastal regions of Africa Proconsularis have proven to be very different. The dominant tendency to turn to the communities formed and structured around native identities, especially those based in the major urban centers and larger areas, seems to establish itself as an argument for the economy and exchanges of the Roman Empire. This types of networks helped to spread ideas and religious symbols through clay lamps. Africa Proconsular demonstrates evidence that the ceramic workshops emerged as networks in order to established themselves seeking to meet the Mediterranean demand and religious consumption.
\end{abstract}

\title{
Keywords
}

Network Science; Archaeological Networks; Classics; Africa Proconsularis.

\section{Análises de Redes e Arqueologia}

Os métodos de Análises de Redes têm sido usados pelos arqueólogos desde a década de 1960, mas apenas na última década um número crescente de estudiosos estão argumentando que a Ciência das Redes tem o potencial de contribuições inovadoras para a Arqueologia e a História (Brughmans, 2014, Brughmans et al., 2015, Isaksen, 2013, Knappett, 2011, Knappett 2013, Peeples et al. 2014, Collar et al., 2015). Arqueólogos são mais afortunados do que historiadores quando se trata da aplicação da teoria das redes, exatamente pelo fato de que a materialidade pode ser quantificada e sua origem no espaço determinada. A intensidade da conectividade provincial é um dos aspectos mais debatidos em economia romana e tanto as fontes arqueológicas quanto as escritas atestam uma grande diversidade de cenários no Mediterrâneo Antigo, demonstrando que a conectividade nunca foi homogênea e algumas regiões eram mais integradas do que outras (Woolf, 2016). 
A recente aplicação das análises de redes em Antiguidade Clássica demonstra que existe uma variedade de abordagens que permitem reconhecer padrões (que de outra forma só poderíamos intuir) e pensar sobre os fenômenos que são produtos dos processos em rede. Nesse sentido, a Ciência das Redes pode ser singelamente definida como "o estudo de modelos de rede" (Brandes et al., 2013: 4). Para além disso, caracteriza-se como um campo acadêmico interdisciplinar que propõe teorias e métodos, incluindo aplicação da teoria dos gratos da Matemática, mecânica estática da Física, modelagem inferencial da Estatística, mineração de dados e visualização de informação da Ciência da Computação, estrutura social da Sociologia, entre outros aspectos teórico-metodológicos agregadores de abordagem. Um modelo de rede representa o processo conceitual pelo qual os pesquisadores passam a perscrutar um determinado fenômeno sob investigação, implícita ou explicitamente, de modo a ser abstraído e abordado sob a égide dos conceitos de rede e as formas que estas assumem.

Um certo nível de abstração é necessário para visualizar, em termos conceituais, o "comércio passado", em termos de rede, com o objetivo de analisar grupos e/ou indivíduos em suas agências, sob o paradigma social das múltiplas interações e através do fluxo de bens e informações comerciais. Entidades sociais podem ser representadas como "nó" e as conexões entre eles são as "ligações" entre os "nós", formando conjuntos (Fleming et al., 2017: 15-16). A abstração necessária para estudar conectividade, em termos de conceitos, e as representações de dados de redes, ocasionam uma profícua fase exploratória de aplicação da Ciência das Redes em Arqueologia (Collar, et al., 2015: 4-5). Sem dúvida alguma o estudo de sistemas urbanos como redes, em que cada cidade forma um vértice ligado a outras cidades através de estradas e vias marítimas, consideradas como estímulos de ligações ou laços, auxiliam a identificar quais cidades são mais centrais (hubs), quais delas foram mais periféricas e quão densamente conectadas estariam no sistema constituído. A Ciência das Redes permite, dessa forma, representar padrões emergentes a respeito do fluxo de informações comerciais e bens inter-cambiados entre as entidades representadas. O emprego desse tipo de análise, a chamada Arqueologia das Redes, não apenas possibilita a tradução de dados arqueológicos em dados de rede, mas também permite testar hipóteses e analises que explore novas quadros de compreensão em relação a um determinado contexto, por consequência distintas táticas hermenêuticas de interpretação.

O estudo de lucernas está inserido nas pesquisas em cerâmica romana e relacionado ao Artesanato e Comércio no Império Romano. Nesse sentido, alinhado as recentes pesquisas em cerâmica arqueológica (Brughmans e Poblome 2016; Bes 2015; Carrignon 2015). A indagação de quão frequente e intensos seriam os contatos econômicos, além dos estudos de caso específicos, é um 
tópico de interesse crescente, fomentando conjuntos de dados que incluem fontes arqueológicas, epigráficas e escritas. O projeto $\mathrm{Orbis}^{2}$, por exemplo, acumula um conjunto de dados que permite gerar inferências e explorar o custo da mobilidade ao longo dos domínios do Império Romano. Outro projeto de destaque é o Pelágios3, que disponibiliza um conjunto de recursos que possibilitam projetar dados em mapas dinâmicos dedicados a diferentes períodos históricos. Esses mapas são de código aberto e gratuitos para uso em pesquisas, ensino e/ou interesse geral.

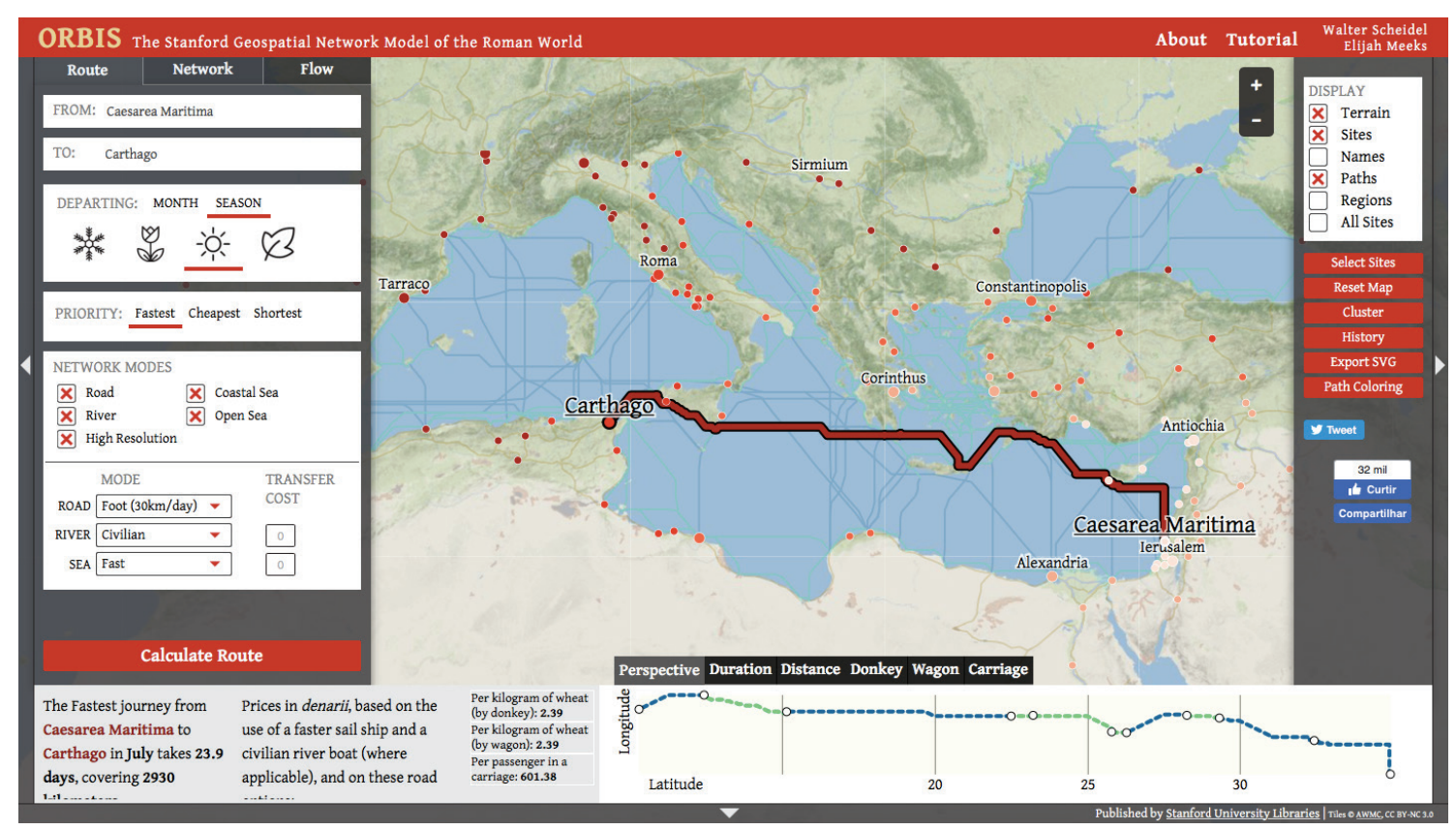

Fig. 1. Projeção da rota entre Caesarea Marítima e Cartago utilizando o ORBIS - Geospatial Network Model of the Roman World.

Conforme salienta Greg Woolf (2016: 43-44), o pensamento sobre redes pode ser muito útil para abordar a mudança religiosa a partir de novas direções, auxiliando a formular descrições mais precisas da mudança social, entendendo-a como um processo que envolve a socialização e a rotinização de atitudes, assim como ritualização. Um processo de aprendizagem, portanto, em acordo com uma maneira particular de imaginar e descrever o cosmos. A teoria das redes permite abordar a questão da mudança religiosa, nesse sentido, a partir de dois modelos de transformação/mudança - a conversão como propagação

\footnotetext{
${ }^{2}$ http:/ / orbis.stanford.edu (The Stanford Geospatial Network Model of the Roman World), EUA.

${ }^{3}$ http://pelagios.org/maps/greco-roman/ (Digital Map of the Roman Empire) Lund University, Sweden.
} 
de ideia e como contágio. Na perspectiva de contágio, além da proximidade, o "recrutamento" religioso pode estar associado ao processo chamado de "lavagem cerebral", em seu sentido mais objetivo, associado a "um atalho para um conjunto de processos psicológicos sociais específicos, dos quais, alguns ou todos podem ser operatórios quando o "ofício mental" é empregado para influenciar uma pessoa ou pessoas" (Taylor, 2004: 95-165).

As observações mencionadas reforçam a idea de que as ordens políticas foram naturalizadas e relacionados às cosmológicas, públicas e cerimoniais na Antiguidade, sendo o templo o edifício foco da religião coletiva e cívica, caracterizando sua autoridade na chamada polis-religiosa. A importância do "culto imperial" na paisagem religiosa das províncias romanas ainda continua a ser debatida com vigor. Essas instituições sociais dependeram fortemente do poder de grupo para o seu sucesso e poderiam ser altamente coercitivas. Os cultos religiosos são geralmente hierárquicos e comumente dominam as paisagens cognitivas de seus seguidores através de seus líderes e locais de adoração. A lavagem cerebral, enquanto fenômeno social fomenta sinapses cerebrais com trajetórias constantes e estímulos automáticos. Pode ser considerada o resultado das interações entre aquele que a transmite e a vítima do processo; é, portanto, pessoal e altamente coercitivo, ou seja segue agenda própria ou age como parte de um sistema social mais amplo de manejo. Esses atributos não têm significado independente, desempenham, na verdade, um grande papel na subjetividade e tornam-se mais importantes quando o grupo os investe com o poder de distinguir seus membros dos de fora do grupo (Ahuja, et al. 1993, Ahuja, et al., 2004, Burke e Kendall, 2014).

Este fenômeno demostra que a ideologia de uma religião será sempre parte da explicação da conversão. Independentemente da capacidade de persuasão de uma ideologia, ou a transcendência de uma visão, a questão da conversão em vez de qualidade de estímulo religioso, pode ser entendida como um processo social, condicionado por redes de pessoas que promovem a mudança religiosa (Collar, 2007: 155-158). É consenso que durante o primeiro milênio da Era Comum a ligação entre a identidade política e a identidade religiosa foi gradualmente se transformando na mesma entidade. Judeus, cristãos e os maniqueístas atraíram substancialmente à atenção das autoridades imperiais e cidadãos romanos, da mesma forma que são relevantes as evidências disponíveis sobre samaritanos, os adoradores de Zeus Hypsistos, de Baco, de Mitra, das divindades sírias e dos cultos egípcios. Paralelos ainda são encontrados em grupos filosóficos como os epicuristas e neoplatônicos. É presumível aceitar, portanto, que entre as comunidades menores o culto coletivo permaneceu importante e que nem todas as mudanças religiosas neste período foram revolucionárias. 
O pensamento de rede nos permite considerar essas grandes mudanças sociais mais claramente. No nível da cidade, através do patronato religioso, benfeitorias foram pagas em sinagogas, grandes templos e centros religiosos para atender os festivais periódicos e prosélitos (Woolf, 2016: 49-50). A inundação de pessoas para participar dos festivais nas cidades e visitar os santuários formaram, essencialmente, duas redes de associação sobrepostas e um terceiro tipo de rede, pode ser identificada, promovida pela interação entre as elites cívicas de algumas regiões para atender a koiné e o concilia provincial, além de outros negócios e interesses. Como bem indicado por Greg Woolf, o impacto de toda esta atividade na criação das elites provinciais-regionais ainda permanece pouco explorado.

Um número cada vez maior de trabalhos lidando com análises de rede têm surgido e trabalhos utilizando Análises de Redes Sociais (ARS) incidem no estudo de indivíduos (pessoas que são entediadas como "nó") e suas relações, estabelecidas através de ligações fortes ou fracos laços, com outros indivíduos. Esses relacionamentos podem ser baseados em parentesco, amizade, ofícios, ou contatos de longa distância. Tipicamente a análise de redes sociais permite mapear indivíduos (nós) em relação a sua centralidade (centralidade do nó) afim de associá-los aos conjuntos estabelecidos (nesse caso clusters). Tornou-se comum identificar ligações mais fortes dos laços mais fracos, aqueles em que a interação acontece com menos frequência. Mais uma vez, o padrão é que alguns indivíduos tendem a ser mais centrais, outros mais periféricos. Como observa o prelúdio de Foucault "o problema é ao mesmo tempo distinguir os acontecimentos, diferenciar as redes e os níveis a que pertencem e reconstituir os fios que os ligam e que fazem com que se engendrem, uns a partir dos outros" (2007: 6). Nesse sentido, é possível abordar as distintas redes de dominação que se recobrem, se amparam e interferem umas nas outras. Não se trata, nesse sentido, de "conceber o indivíduo como uma espécie de núcleo elementar, átomo primitivo, matéria múltipla e inerte que o poder golpearia e sobre o qual se aplicaria, submetendo os indivíduos ou estraçalhando-os"; mas efetivamente compreender que "aquilo que faz com que um corpo, gestos, discursos e desejos sejam identificados e constituídos enquanto indivíduos é um dos primeiros efeitos de poder" (p.90-103).

O pensamento de Bruno Latour (2005) convida analistas a explorar a rede múltipla de relacionamentos entre os seres humanos e agentes não-humanos, assim como os papéis de cada um nas seqüências de mudança. A chamada Teoria Ator-Rede (TAR) se originou na área de estudos da ciência, tecnologia e sociedade desde de 1980 e também é conhecida como "sociologia da tradução". Procura dar conta de novos paradigmas de comunicação e, por consequência, abarca a agência de cultura material como catalisador de mudanças. Anna Collar (2013a, 2013b) demonstrou que a análise de ponto proximal (PPA), para gerar redes a partir de distribuições, é uma poderosa ferramenta 
heurística, permitindo-nos imaginar tipos de conexões para explicar sua dispersão, e os diferentes tipos de conexões necessárias para preservar a integridade das tradições alienígenas entre aqueles que não as compartilharam em outras regiões. Cada nó, nesse caso, conecta-se aos três mais próximos, e assim áreas de distribuição mais densa formam clusters. $\mathrm{O}$ "pequeno-mundo" é um fenômeno de rede global que surge a partir das interações de rede local e através de pontos nodais que determinadas comunidades estariam estreitamente ligadas (Collar, 2013a: 224). A maior parte dos indivíduos pode estar envolvido com muitos aspectos da rede social local, denominada de tipo "ligação-forte", mas também podem estar envolvidos em relações de longa distância, denominada de tipo "ligação-fraca". Quando se trata da transmissão "complexa" de novas ideias ou da disseminação de ideias religiosas, a cultura material pode agir como núcleo manipulador e fomentar referenciais para as decisões da rede de contatos. Judeus integrados com as comunidades locais no início do período helenístico-romano envolveram-se com muitos aspectos da cultura greco-romana e adotaram nomes e práticas helenizadas (Collar, 2013b: 223-246).

$\mathrm{O}$ ambiente romano fortaleceu laços interpessoais entre as comunidades judaicas e a destruição do Templo de Jerusalém (בית המקדש, beit hamiqdash) mudou drasticamente a vida dos judeus da Palaestina Romana. A tensão resultou na reativação das redes de tipo "ligação-forte" pelo Mediterrâneo Antigo, construídas em uma nova compreensão da etnicidade compartilhada entre os judeus da Diáspora. Josefo localizou a essência do Judaísmo de seu período nos ritos do Templo em Jerusalém e lamentou a destruição das obras literárias da Diáspora Judaica, como os Oráculos Sibilinos Quarto e Quinto, por exemplo (Collins, 1986: 152, Goodman, 1994: 45). As mudanças ocorridas para a maioria dos judeus da Diáspora tiveram o efeito do afluxo de refugiados da Iudaea-Palaestina e/ ou prisioneiros de guerra, bem como a maior mobilidade de comerciantes e mercadores que testemunharam a transformação do imposto do Templo de Jerusalém se transformar para o fisco especificamente judaico dentro dos limites do Orbis Romanorum. A conectividade das redes judaicas foi renovada pela expulsão dos judeus de Jerusalém e a consequente dispersão regional e pelo mediterrânea durante os $3^{\circ}-4^{\circ}$ séculos EC acabaram reconfigurando as redes locais e extra-provinciais de contatos: destacando as ligações com a Fenícia e criando uma rede interna mais forte de contatos e novas ligações com a Cilícia e o norte da África (Collar, 2013a: 234).

O Cristianismo, por sua vez, se espalhou primariamente dentro das áreas de assentamento judaico e há uma distinção fundamental entre a distribuição espacial e temporal da emergente "nova tradição" em relação a outros fenômenos da sociedade romana. É importante salientar que o Egito exerceu um papel importante para o Cristianismo emergente, portanto, um ponto nodal 
de afluência e propagação do seu pensamento. Cumpri lembrar que a ideia do trinitarismo foi representada por Atanásio de Alexandria face a ideia do arianismo que foi partilhada, até onde se sabe, por Eusébio de Cesareia na Palaestina Romana (Ramalho, 2013).

A Teoria das redes tem o potencial de analisar a forma que a informação foi disseminada. Obviamente que as estruturas sociais não são estáticas, mas perpassam um fluxo de informação e energia, assim como flutuações que podem levar a mudanças súbitas nos níveis de escala e complexidade de fenômeno. As abordagens de rede procuram, nesse sentido, precisar a origem de uma estrutura social, representando as redes emergentes que são produzidas pelo fluxo de informação. $\mathrm{O}$ emprego do pensamento de rede para a transmissão de idéias religiosas, imagens e práticas, possibilita, além da abordagem por contágio, ora explicitada, também a compreensão geral do fenômeno pelo qual as inovações são disseminadas através de uma rede, comparável à adoção de novas culturas e novas tecnologias (e.g. Stark, 1996, Mann, 1986).

A aplicação mais comum da teoria de redes tem sido a maneira de considerar as interações culturais através das distâncias significativas. Uma estratégia heurística que nos incentiva a pensar em termos de relacionamentos entre as entidades-pessoas e as materialidades-coisas, a partir da suposição de que todos os tipos de novas ideias e materialidade estão sendo constantemente geradas, e estamos em constante processo de seleção e adaptação (Knappett, 2011). O argumento lida com duas etapas distintas de pensamento, sendo a primeira a das origens da religião e a segunda sobre o tipo de seleção natural das formas religiosas. A primeiro diz respeito a suscetibilidade que a humana de forma geral possui por esse tipo de representações, características da cognição que evoluíram devido a vantagens que transmitiram. A segunda etapa é mais importante, pois concentra a atenção nos processos de seleção cultural que fizeram certas formas de culto mais bem sucedidas que outras, considerando quais aspectos (ou affordances) que foram considerados particularmente adequados para exportação, assim como quais tipos de ambientes sociais eram particularmente suscetíveis a esses apelos. O mapeando e análise de redes em Arqueologia oferece uma parte importante da resposta, mas sempre necessitam ser complementados com mais informações arqueológicas contextuais específicas e regionais. Conceituar dados arqueológicos como dados de rede, portanto, permite que os dados sejam analisados usando diferentes técnicas e métodos da Ciência das Redes, tratados com mais detalhes e afinco por outros autores (e.g. Newman, 2010, Scott e Carrington, 2011, Wasserman e Faust, 1994).

As visualizações geográficas são especialmente úteis e merecem uma menção, pois colocam a rede em um contexto arqueologicamente reconhecível. Os mapas são organizados por coordenadas geográficas e muitos também incluem visualizações de redes organizadas. Essa justaposição visual de aspectos 
geográficos e outros layouts de rede permite analisar o impacto potencial da geografia sobre as relações sociais nos conjuntos de dados sob investigação. Auxilia a criação e agrega dezenas de bancos de dados diferentes detendo a capacidade de gerar uma visão multifacetada do mundo clássico. Esta coleção de evidências é um passo crítico para entender a economia romana e outras representações na Antiguidade, bem como o seu uso. No Mediterrâneo Romano, além da emergência de novas redes de comércio e contato, estamos sempre lidando com o binômio da heterogeneização e homogeneização da paisagem cultural e religiosa tanto quanto com as complexificações dessas relações. Muitos empréstimos entre grupos religiosos foram proporcionando a criação de novas fronteiras culturais, e, assim, mistérios, astrologia e o uso de textos sagrados, foram exemplos de tecnologias religiosas apropriadas, não apenas para tornar um novo grupo mais distinto de outro, mas também para movimentar a relação do fluxo de bens e informações comerciais. O pluralismo religioso implicou a criação de diferenças e suas constantes sinalizações e reconhecimentos.

\section{Centros de manufaturas e Padrões de Distribuição Intraregional e Interregional}

O entendimento geral de que Roma gozava de um sistema econômico que era "um enorme conglomerado de mercados interdependentes" têm sido amplamente debatido. A abordagem de Temin (2001:169-181) faz referência a Polanyi essencialmente no que diz respeito as categorias de intercambio (redistribuição, reciprocidade e mercado). O autor observa a existência de cunhagem, preços, taxas de juros, contratos, preocupações com a lucratividade, e vários comportamentos econômicos inteligentes. Em sua opinião, até mesmo as empresas agrícolas interioranas estavam cientes em suas previsões econômicas dos preços negociados, centrais para as transações mercantis, conforme as ofertas e demandas que estavam economicamente conectadas. O Império Romano seria, nesse sentido, composto por uma economia de mercados, todos interconectados, alguns mais que outros, dependendo da região.

A maioria dos estudiosos concorda que uma mistura complexa de mecanismos que trabalharam em vários níveis foi responsável pelas diferenças nos padrões de distribuição e consumo de cerâmica pelo Mediterrâneo Antigo durante o período Romano. Modelos conceituais descritivos foram propostos para explicar o funcionamento do comércio e dos mercados na estrutura imperial romana, que funcionariam muito mais sob o estilo de 'mercado-bazar' no período em questão (Bang, 2008: 4, Bes, 2015; Brughans e Poblome, 2016: 398). Completamente diferente do estilo de entidades integradas em grande escala de produção e com informação especializada, facilitada por uma extensa 
e eficiente rede de comunicação, tal qual acontece nos dias atuais. O mercado romano, por outro lado, parece ter funcionado muito mais como um sistema fragmentado com relativa padronização, do qual os próprios comerciantes e mercadores tinham um determinado tipo de conhecimento, muitas vezes limitado (o que favoreceria o oportunismo e especulação). Dessa forma, o comércio romano eminentemente se estabeleceria a partir da rede social de relações de confiança pessoal e fortes laços comunitários mantidos; assim como pelas demandas variáveis de consumo local e regional, assim como pelas incertezas ambientais de transportes e transparências do mercado.

Peter Bang (2008: 200-201) sugere que as redes sociais permitiram a especialização dos intermediários e do comércio inter-regional, de maneira que isto fomentou uma integração das esferas políticas e comerciais. Ele argumenta ainda que os comerciantes tinham a tendência dominante de voltar-se para as comunidades formadas e estruturadas em torno de identidades nativas, especialmente aquelas assentadas nos principais centros urbanos e áreas maiores do Império Romano. Ao contrário de Bang, no entanto, Temin (2014: 4) acredita que os mercados romanos foram integrados e fortemente interligados, inclusive em grandes distâncias. A economia do início do Império Romano, embora não tão articulada como a atual, evidencia suficiente materialidade para apontar que estava organizada como um sistema de mercado interligado que se assemelharia à Europa e Américas durante o $18^{\circ}$ século EC (Tchernia, 2016: 74). Um elemento chave dessa integração foi o exército romano e seu suprimento, exigido em grande quantidades de produtos (Scheidel, 1997, Scheidel, et al., 2002, Scheidel, et al., 2007). A produção e transporte de azeite da província da Hispânia Bética (Hispania Baetica) para a Britânia (Britanniae) após a conquista romana aumentou a demanda imperial e parece ser um exemplo bem ilustrativo (Remesal Rodriguez, 1986, Remesal Rodriguez, 2011: 60). As mercadorias básicas foram distribuídas entre os assédios militares romanos, mas parece provável que a rede de comércio se expandiu para abastecer assentamentos civis e os bens de consumo foram distribuídos para centros urbanos usando redes de redistribuição militar. A economia romana foi formada por províncias com produções especializadas que exigiram um comércio em grande escala.

A produção da cerâmica africana de verniz-engobe-esmalte vermelho (ARS-African Red Slip) supostamente emergiu na região norte da Tunísia, especificamente nas imediações de Cartago, com a finalidade de suprir o mercado intra-provincial (Hayes, 1972: 296; Hayes, 2001; Fleming 2018: 431-445). As analises em âmbito regional e supra-regional permitem acessar uma consciência crescente de que as perspectivas de produções em grande escala são cada vez mais capazes de explicar, ou pelo menos melhorar a compreensão, de certos fenômenos políticos, sociais e econômicos da África romana. Como 
apontado por Bes e Poblome (2007) trata-se de uma mudança de atitude para com os tempos e metodologias de estudos de cerâmica romanas. A produção inicial de cerâmica na África Proconsular imitava modelos em Terra Sigillata italianos, e a evidência é de que as primeiras formas de cerâmica com verniz vermelho (ARS), datadas do no final do primeiro século EC na necrópole de Tipasa e Sétif (Guéry, 1979, Guéry, 1987: 132-133), permitem concluir que mudanças foram adotadas nos projetos iniciais e os modelos evoluíram com o tempo no processo de fabricação em massa dessas cerâmicas, conforme as demandas intra-regional e inter-regional. Distintas formas de cerâmica africana de engole vermelho foram distribuídas a partir da região de Cartago e seu afluxo de contatos. A efetiva circulação e distribuição das novas cerâmicas africanas dependeu essencialmente da localização dos centros de produção, uns estrategicamente posicionados na costa e outros no interior da província.

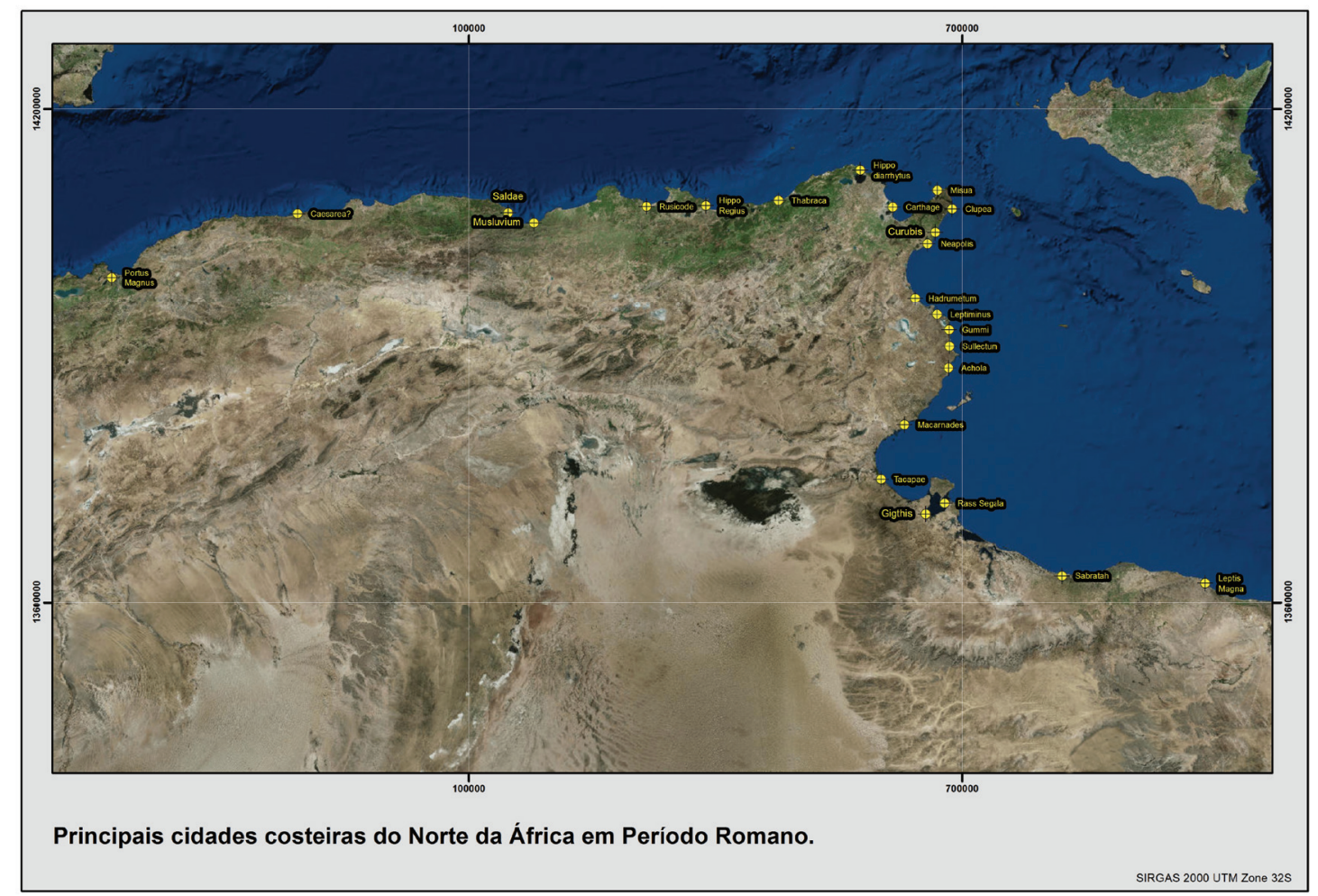

Fig. 2. Principais cidades costeiras do Norte da África em Período Romano

Por volta do século $2^{\circ} \mathrm{EC}$ em diante, a produção de cerâmica de verniz vermelho tornou-se autônoma, com o surgimento de novas formas, denominados de Hayes 27, 29-33 e 43-44 (Hayes, 1972: 15; Heslin, 2008: 62). Aparentemente, durante o início do século $3^{\circ} \mathrm{EC}$ a produção local sobrepôs-se à importação (com o aumento do tamanho médio das vasilhas) e uma distribuição intra-provincial de mercado concentrada na produção das oficinas das regiões leste 
e central da Tunísia. Longe dos centros manufatureiros da região norte de Cartago, durante o final do $3^{\circ}$ e início do $4^{\circ}$ sécs. EC, os centros produtores de Kasserine, de Henchir-es- Srira e Sidi Aich, abasteceram os mercados locais e seus produtos foram difundidos através do leste da Tripolitânia, bem como na região ocidental de Bizacena e Numídia. Portanto, a manufatura africana da cerâmica com verniz vermelho (ARS) cresceu quantitativamente e em importância geográfica no decurso do $3^{\circ}$ século EC no Mediterrâneo Antigo. Esse padrão tornou-se ainda mais condensado a partir da segunda metade do $4^{\mathrm{o}}$ séc. e início do $5^{\circ} \mathrm{EC}$. Durante este período se considera que o Norte da África fez parte completamente da koiné de distribuição de utensílios cerâmicos pelo Mediterrâneo Antigo (Bonifay, 2005a: 566-568).

Dessa forma, a produção africana de cerâmica de engobe vermelho estabeleceu um domínio substancial a partir do $2^{\circ}$ e $3^{\circ}$ sécs. EC, espalhando sua produção e extendendo-se temporalmente até metade do $4^{\circ}$ séc. EC pelo Mediterrâneo Antigo em grande escala, uma exportação supra-regional que continuou ao longo de mais de três séculos pelo menos. Um segundo florescimento de distribuição cerâmica parece ter ocorrido durante o $5^{\circ}$ séc. e início do $6^{\circ}$ séc. EC. A partir do $7^{\circ}$ séc. EC em diante os achados cerâmicos de ARS são mais raros. Nestas circunstâncias, o controle das rotas marítimas certamente ajudou a consolidar o domínio mercantil para demanda de cerâmicas e comercialização. Fatores culturais desempenharam o papel principal no controle dessas rotas comerciais, apesar de fatores naturais também afetarem as flutuações de mercadorias negociadas em certas rotas marítimas.

Os diferentes níveis geográficos englobaram direta e/ou indiretamente os contatos entre assentamentos e sítios, mas principalmente as trocas culturais e relações comerciais ocorreram sob o regime de diversas motivações e em diferentes enquadramentos culturais, sugerindo que uma intensidade relativa de distribuição de bens teria conectado regiões em diferentes níveis, tais como a África Procunsular e a Palaestina. Os padrões de troca e inter-fluxo entre as províncias parecem ter ocorrido tanto pelas rotas marítimas no contato entre cidade costeiras, quanto pelas rotas terrestres e vias que conectavam o Império Romano (Bes e Poblome, 2007: 8-9). A cerâmica africana fina de verniz vermelho parece ter sido comercializada em todo o Império Romano e foi amplamente popular. A ideia de que a maioria dos produtores de cerâmica fina eram de oficinas de pequena escala localizadas em propriedades rurais ou nas periferias das cidades, de onde distribuíam seus produtos, corresponde a uma aparente realidade em muitas regiões do Oriente e também do Ocidente (Lewit, 2011: 314-315).

Eventualmente, essas indústrias de cerâmica local e regional expandiram-se para produzir em uma escala maior, não apenas para aumentar a produção, 
mas também para exportar ideias e símbolos para um mercado muito mais amplo. Reynolds (2010: 90-93) destaca que a cerâmica africana de verniz vermelho em Beirute torna-se de $51 \%$ da amostragem de cerâmicas finas em meados do $3^{\circ}$ séc. EC. para mais de $91 \%$ da amostragem durante a metade do $4^{\circ}$ séc. EC. Símbolos judaicos e cristãos foram retratados na parte central das lucernas cerâmicas africanas, substituindo aqueles ícones e temas que foram dedicados ao politeísmo greco-romano, ajudando a transformar e estabelecer diferentes graus de interação cultural e consumo entre a Palaestina e o norte da África Romana.

O consumo de lucernas e os significados atribuídos a essa prática (que se relacionam com as metáforas da luz e os rituais de iluminação em sociedade) desenvolveram-se sob a ordem de um conjunto particular de estímulos excepcionais, dentre os quais a ascensão do cristianismo e as redes de contado da Diáspora Judaica, exerceram dinâmicas próprias para os contextos de consumo, tornando-se, muitas vezes, indicadores de clientela nos padrões de fluxo de troca do Mediterrâneo (Lapp 2006). Bonifay (2005b) tentou conciliar a tipologia cerâmica das cerâmicas de engole vermelho e a pesquisa petrogáfica dos artefatos com o objetivo de localizar oficinas cerâmicas na África Proconsular. O arqueólogo concentrou seus esforços em três cidades vizinhas da necrópole de Pupput, além de Sidi Jdid e Nabeul (no norte do Golfo de Hammamet) e no sítio de Rougga-Bararus (perto de El Jem). Durante a escavação de uma necrópole urbana em Pupput (Hammamet) em atividade durante o $2^{\circ}$ ao $4^{\circ}$ séculos EC, cerca de 600 lucernas africanas Terra Sigillata foram encontradas. Em Sidi Jdidi (Aradi) as lâmpadas foram encontradas relacionadas a iluminação de três basílicas cristãs, datadas entre o $5^{\circ}$ e $7^{\circ}$ séculos EC.

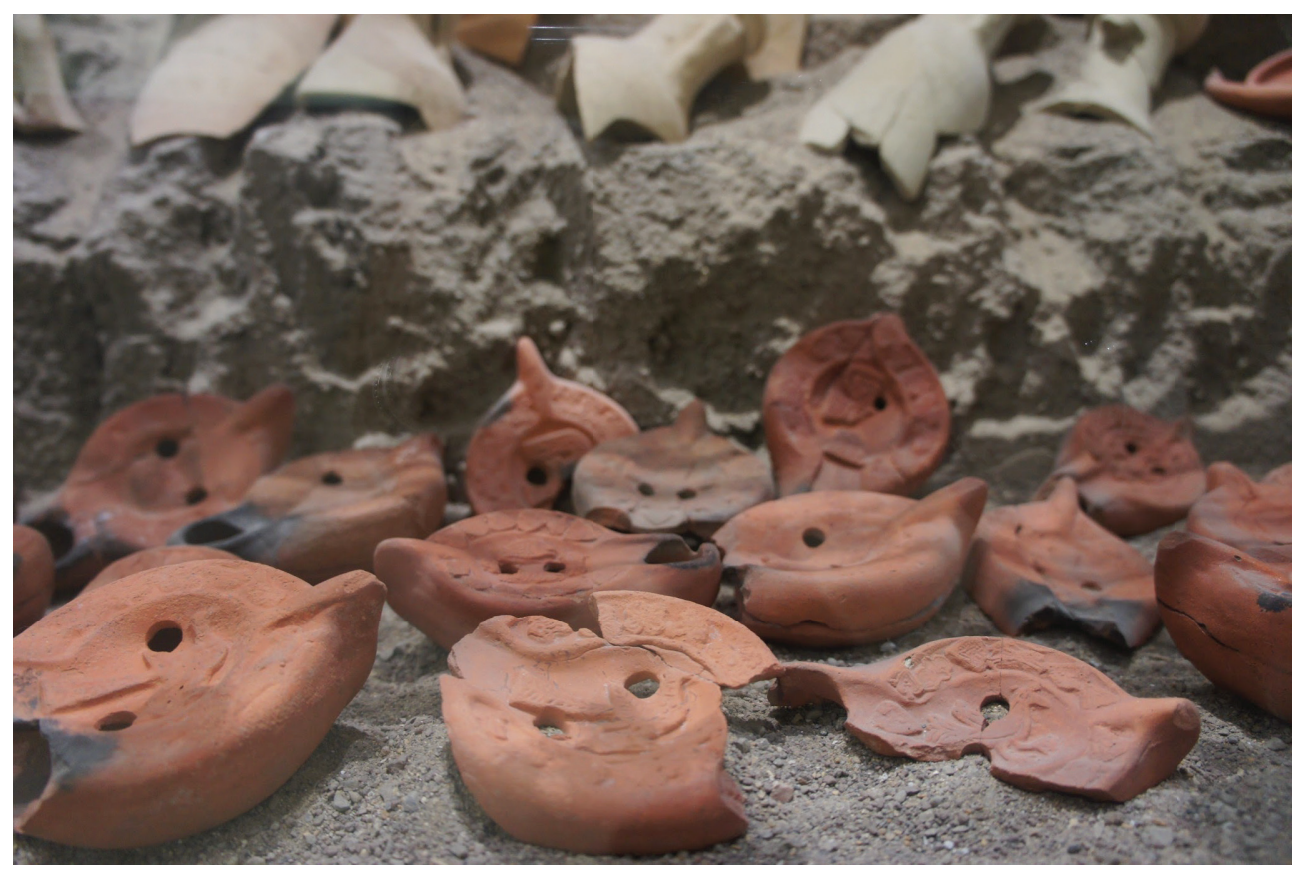

Fig. 3. Lucernas norte-africanas, cerâmicas de engobe vermelho. 
As análises contextuais dos sítios acima mencionados, portanto, permitem que o autor classifique as lâmpadas sob investigação em três categorias principais: lâmpadas africanas com bico redondo e/ou em forma de coração (Deneauve 1969, Deneauve 1972, tipo VII e VIII), lâmpadas africanas de tradição tardia (derivadas dos tipos Deneauve VII, Deneuve VIII, Deneuve XI B [= grupo Rossiter 6]), e as lâmpadas em Sigillata Africana (Tipos Hayes II A, Hayes II B [grupos sigillata africana C e D]) (Deneauve, 1986: 141-161).

No norte e centro da Tunísia concentraram claramente as atividades de oficinas de ARS do $1^{\circ}$ ao $7^{\circ}$ sécs. EC. Parece que até o final do $2^{\circ}$ séc. EC, os fornos mais ativos estavam situados no norte da África Proconsular, talvez na vizinhança de Cartago (Oudhna). Nos $3^{\circ}-4^{\circ}$ sécs. EC, uma nova onda de produção surgiu, originada no centro de Bizacena e particularmente El Mahrine recuperou sua importância e exportou para todo o Mediterrâneo (Bonifay, 2004: 47-8). Durante o $5^{\circ}$ séc. EC, a ARS do período vândalo foi produzida por unidades no centro de Bizacena (Sidi Marzouk Tounsi), a região de Cartago recuperou sua hegemonia na produção e comércio ao longo da metade do $5^{\circ}$ séc. EC. Já em Nabeul (Neapolis) foram encontradas lucernas em uma fábrica de salga de peixe apresentando uma estratigrafia contínua do $1^{\circ}$ ao $7^{\circ}$ séculos EC. Finalmente, em Rougga (Bararus) as lucernas da reocupação do fórum correspondem a níveis que cobrem o período entre o $7^{\circ}-8^{\circ}$ séculos EC.

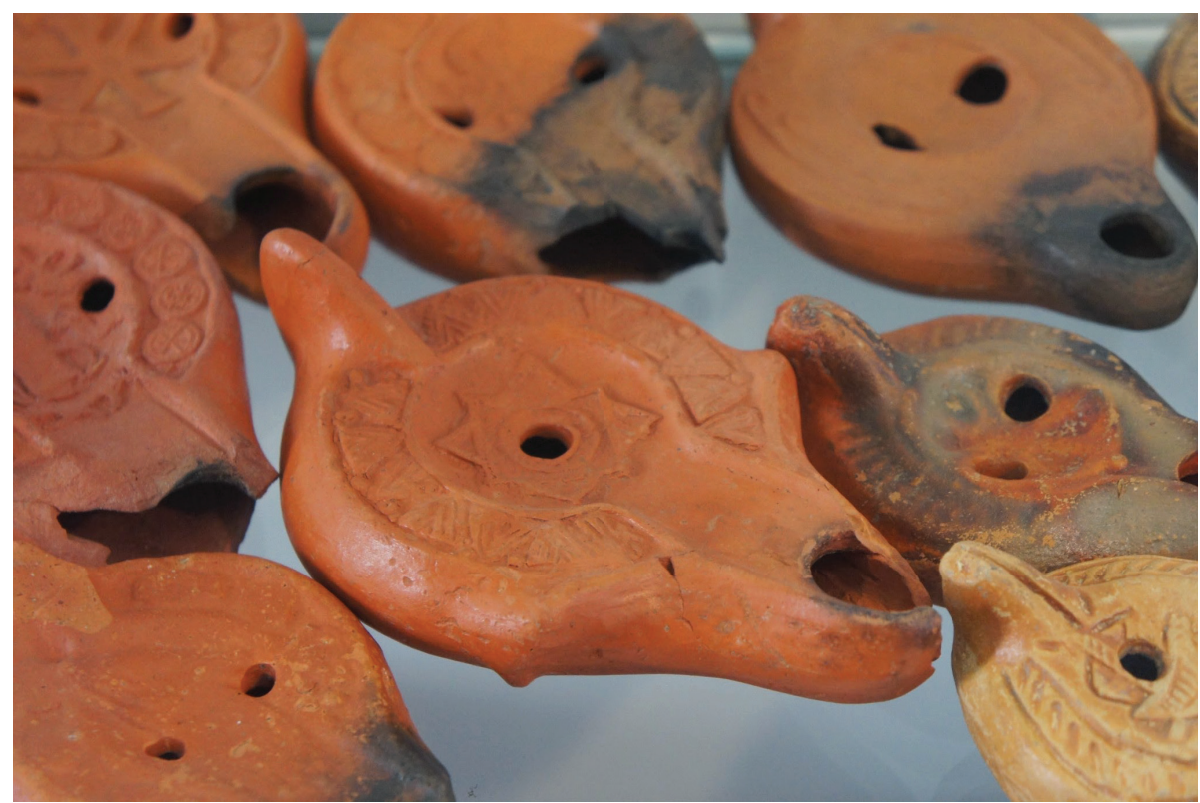

Fig. 4. Lucernas africanas Terra Sigillata com iconografia judaica e cristã.

Existe evidência substancial sobre a produção na costa da Tunísia, principalmente para a região de Cartago, mas também para a região de Clupea / Kelibia, 
Neapolis / Nabeul, Pupput, Sidi Jdidi, Leptiminus, Bararus / Rougga e Jerba. Basicamente, os contextos costeiros de produção cerâmica são raros na Argélia, sendo possível apenas mencionar Cesareia / Cherchell, a vila de Nador, Tipasa, Driaria el-Achour, Rusguniae, Hippo Regius / Annaba, e as escavações de resgate em Icosium / Algiers. A informação disponível a partir da Líbia vem de Sabratha e Leptis Magna e também é documentada para regiões do interior: Setif, Tibessa, Maktar, Ucchi Maius, Althiburos, Hadra e Lambésis. Essas evidências arqueológicas de oficinas cerâmicas são completadas por vários estudos realizados tanto em regiões costeiras como interiores do norte da África. Na Tunísia, encontram-se oficinas cerâmicas romanas também em torno torno das áreas de Dougga, Segermes e Passerine; na Argélia, em torno de Diana, Cherchell e Veteranorum / Zana; e na Líbia, no centro da Tripolitânia (Bonifay, 2013: 530-531).

Onipresente em todas as oficinas de ARS reconhecidas na Tunísia (por exemplo, El Mahrine, Sidi Marzouk Tounsi, Henchir es-Srira, Hencir el-Gellal Djilma e Oudhna), a tradição de verniz vermelho na produção de cerâmica da África pode ser identificada através dos restos de ferramentas de queima nos chamados saggars. Saggars são caixas cilíndricas de argila, de boca larga numa extremidade e mais estreita, na outra, na qual a cerâmica deve ser colocada para ser cozida. A comparação com técnicas usadas em oficinas modernas de faiança sugere que saggars foram empilhados em cima uns dos outros, formando torres dentro do forno. $\mathrm{O}$ único forno de cerâmica africana Terra Sigillata de verniz vermelho até agora escavado em Oudhna indica que dentro de um saggar havia espaço para cerca de 12 lâmpadas, e que cerca de 180 saggars poderiam ser colocados dentro de um forno, dando uma carga total de queima de mais de 2000 peças.

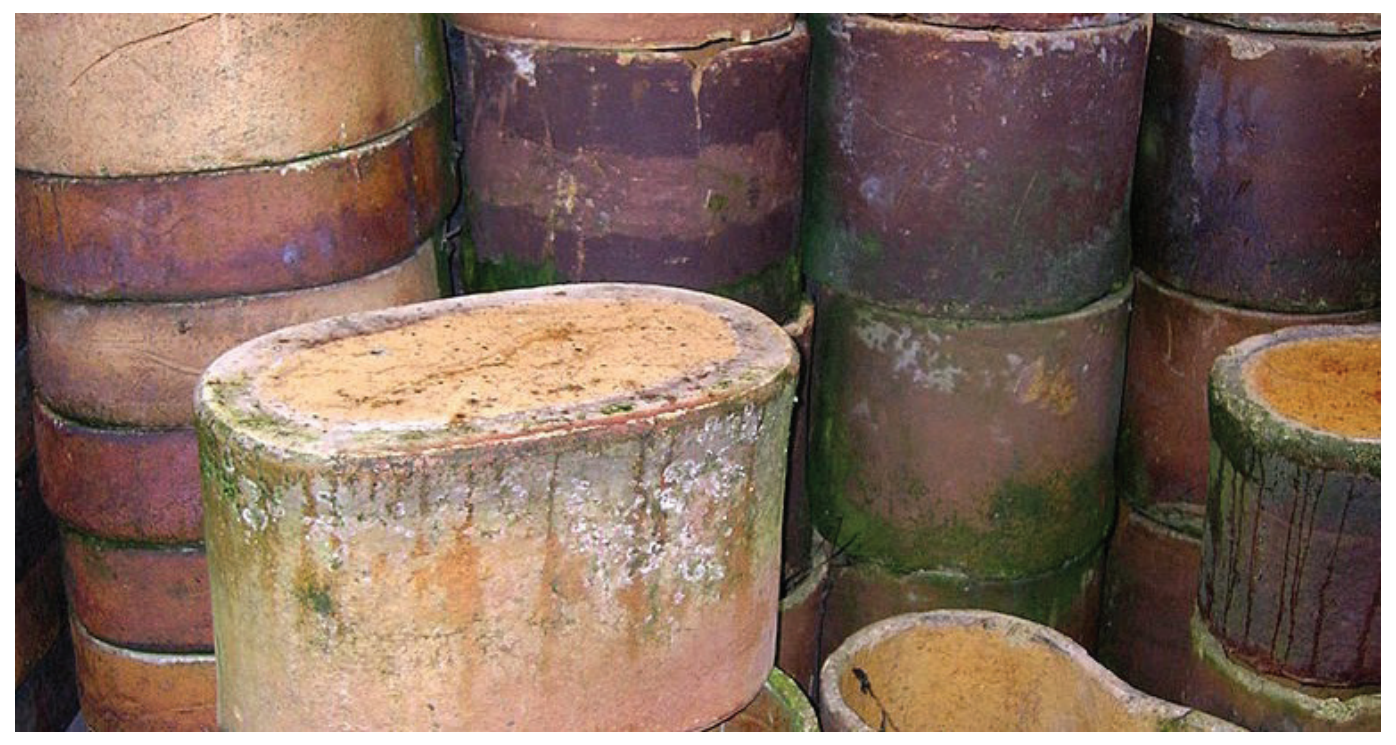

Fig. 5. Saggars, caixas cilíndricas de argila para produção de cerâmica. 
A partir da segunda metade do $6^{\circ}$ séc. o processo de fabricação sofisticado dessas lucernas, que compreendia a sobremodelagem de um arquétipo de barro, para produzir os moldes de gesso definitivos, foi progressivamente abandonado (Mackensen, 1993: 101-105). No final do $7^{\circ}$ séc. EC, um novo estilo decorativo com padrões lineares e mais ingênuos apareceu e lucernas do tipo Hayes II mostram evidências da decoração borrada, muito provavelmente causada pelo uso contínuo dos mesmos moldes (Bonifay, 2004, 81, fig. 231). As lucernas importadas são raramente encontradas nos contextos arqueológicos norte-africanos, as evidencias encontradas são do período bizantino tardio (século $7^{\circ} \mathrm{EC}$ em diante). Devido a pouca quantidade, a distribuição de cerâmicas finas não pode ser comparada em lucernas importadas versus lucernas de consumo interno, embora padrões continentais versus padrões costeiros de consumo possam fornecer hipóteses interessantes sobre os bens de consumo no interior e na costa da África Proconsular (Bonifay, 2007: 152). As finas cerâmicas africanas de verniz vermelho chegaram a atingir regiões com mais de $450 \mathrm{~km}$ de distância (por exemplo, a produção da oficina de Sidi Marzouk Tounis para região de Sétif). As lucernas produzidas na Tunísia central foram importadas em grande escala até o final do $5^{\circ}$ e início do $6^{\circ}$ séculos EC (Bonifay, 2013: 554). Os produtos cerâmicos africanos locais e regionais estiveram em interação nos grandes assentamentos e principais cidades romanas localizadas ao longo da rede de estradas e afluxos portuários do Mediterrâneo Antigo.

\section{Consumo e Identidade através da materialidade}

Em torno de 350 EC, o mercado do Mediterrâneo Antigo foi inundado pela cerâmica africana, a comercialização de azeite, salsamenta (que inclui tanto $g a$ rum como peixe salgado sólido) e vinho, parece ter associado a cerâmica à grande produção e distribuição de alimentos e provisões. Carregamentos de ânforas foram, por vezes, suplementadas com cerâmica de cozinha e doméstica e a partir do século $5^{\circ}$ EC é possível atestar ampla distribuição de ânforas de tradição púnica em Sitifensis, na Bizacena costeira e na parte norte do Golfo de Hammamet (Bonifay, 2007; Capelli e Bonifay, 2014: 240). Uma continuidade pode ser observada nas regiões do Mediterrâneo Oriental com a tradição fenícia, depois que as ânforas greco-romanas (tipo LR) haviam cessado na Cilícia. A produção da ânfora de Gaza (tipos 4 LR e 5-6 LR) continuaram a ser encontradas inclusive durante as camadas do período islâmico, atestando materialmente o longo período de inter-fluxo e contato (Bonifay, 2007: 145).

Os padrões de consumo de cerâmica no interior e nas regiões costeiras da África Proconsular demostraram ser muito diferentes. Na verdade, as cidades próximas à costa demonstram um padrão muito local de fornecimento (por 
exemplo Aradi / Sidi Jdidi), enquanto grandes cidades do interior receberam diversas importações do Mediterrâneo (por exemplo Thysdrus / El Jem) especialmente durante o $4^{\circ}$ século EC. Evidências apontam que as oficinas de Cartago forneceriam cerâmicas "clássicas" ARS (sigillata tipo D) e ânforas romanas tardias do Mediterrâneo oriental através dos portos do vale do Mejerda até fazendas remotas e cidades como Uchi Maius e Aïn Wassel, perto de Dougga. Apesar da distância da costa, a região do pré-deserto entre Leptis Magna e os limes da Tripolitânia foram aparentemente abertos às importações do Mediterrâneo Antigo, como atesta o fornecimento de cerâmica no forte de Gheriat el-Garbia, cerca de $250 \mathrm{~km}$ do mar (Bonifay 2013: 552 ).

As evidências arqueológicas disponíveis sugerem que os tipos de lucernas norte tunisianas (Atlante VIII C1D, VIII D e grupo X D3) podem ser encontradas em zonas costeiras, como Hippo Regius ou Tipasa, e Leptis Magna (Bonifay, 2013: 548; Bussière, 2008, 2012). Aparentemente, a maioria das lucernas encontradas na Argélia é oriunda das manufaturas da Tunísia central (tipo Atlante $X$, grupo C2-4), principalmente aquelas encontradas em zonas interiores (por exemplo, Djemila, Sétif, Lambésis, Timgad, e Tipasa). As principais cidades portuárias, como Annaba e Cherchell, assim como as oficinas do sul da Tunísia operando em Sidi Aich também comerciaram seus produtos para zonas interioranas (Bonifay 2013: 548).

Neste sentido, a produção local inspirada pelas formas de tradição romana itálica não estavam restritas ao consumo das zonas interioranas e atestam em uma faixa muito estreita do litoral norte africano. A região de Cartago e a região ao norte do Golfo de Hammamet mantiveram as suas próprias quantidades e modelos sendo negociadas no litoral Africano. Um considerável número de moldes de argila de lucernas ARS da Tunísia central foi encontrado em Tiddis, Djemila e Timgad, materiais sem verniz; e os sítios de Tipasa e Hippo Regius atestam produções locais com características muito distintas das lucernas ARS do $4^{\circ}$ ao $5^{\circ}$ séculos EC (por exemplo Atlante VIII e as com a inscrição 'de officina assenis'). Ao longo do mesmo período, a Tripolitânia tem suas próprias oficinas cerâmicas de produção de lucernas.

Em suma, o mercado africano era forte no interior (pequenas cidades tiveram produções e mercados locais) e as regiões da costa, capitalizaram posição estratégica para interligar a bacia do Mediterrâneo com as regiões do interior norte Africano, através do suprimento e comércio de vinho, azeite e produtos derivados de peixe, assim como as cerâmicas de alta qualidade. Assim, um comércio inter-provincial (posteriormente 'intra-diosesano') aparentemente existiu e aponta para uma forte troca interna (Bonifay, 2013: 557, Wickham, 2005: 720-728). Como apontado pelas evidências arqueológicas, as regiões do interior receberam não apenas as lucernas e cerâmicas de mesa do centro e 
do sul de Bizacena, mas também vinho e grãos que chegaram da costa do Mediterrâneo em larga escala, pelo menos desde o $3^{\circ}$ século EC. A rede de estradas leste-oeste com as cadeias de montanhas que dividem a paisagem em faixas latitudinais, e os rios navegáveis, certamente, possibilitaram o desenvolvimento de tais relações de intercâmbio comercial na geografia particular do Magrebe durante a Antiguidade Tardia. Sem dúvida o transporte por mar, principalmente a partir de Cartago, Zeugitana e Bizacena (leste e oeste), favoreceu o crescimento e fornecimento da produção cerâmica africana (com o apogeu de distribuição da African Red Slip). As lucernas, produtos tão necessários, foram operadas em baixos custos, acessíveis sob demanda de gostos e clientela social, que por sua vez ajudaram a fomentar o inter-fluxo cultural e as relações de troca através dos objetos.

\section{Conclusão}

A cerâmica africana de verniz vermelho foi freqüentemente produzida no interior, como parte ou perto especialmente das regiões de produção de azeite, assim como esteve presente na região costeira, onde frequentemente ocorreram a manufatura de cerâmicas de cozinha, vasos e ânforas para estocagem e transporte marítimo. Embora Oudhana e Sidi Khalife sejam locais bem conhecidos do interior norte africano com a presença de fornos (pelo menos 30$45 \mathrm{~km}$ distantes da costa), as oficinas cerâmicas de El Mahrine e Sidi Marzouk Tounsi, embora sejam sítios com pelo menos 100 km de distância para o interior e separado por faixa de montanhas, evidência produção de cerâmica em alta escala e distribuição. O que demonstra que no caso africano as oficinas cerâmicas se concentraram próximas as empresas agrícolas da produção de azeite, como forma de acesso aos resíduos e óleo para uso combustível na queima das cerâmicas. No litoral, os sítios de Cartago e Lepitiminus (talvez Sabbath e Leptis Magna) mostram evidências que permitem concentrar as condições de calor necessárias para grandes produções de cerâmicas finas (com queima superior a $700^{\circ} \mathrm{C}$ ), bem como indicam ter artesãos especializados para controlar as técnicas de manufatura e fazer parte do mercado de cerâmica e lucernas. Assim, a produção de cerâmica africana de verniz vermelho (ARS) foi localizada principalmente em locais do interior da Tunísia, de onde a rica produção de azeite foi transportada para a costa, inicialmente em odres, presumivelmente para reduzir o peso e transportar mais quantidade, e, posteriormente, em ânforas fabricadas nas proximidades dos portos das cidades costeiras para distribuição pelo Mediterrâneo Romano (Lewit 2011: 320).

O norte de África fornece evidências que permitem concluir que figuras, signos e símbolos do Oriente foram apropriados pelo cristianismo da tradição local. Um grande número de estatuetas de barro foi encontrado em Cartago, 
muitas que retratam uma deusa-mãe, remetendo a tradição Púnica, sentada em um assento a amamentar uma criança. Posteriormente essas imagens e alegorias foram aproprias a figura cristã de Maria, mãe de Jesus Cristo. Essa associação está em interação iconográfica com a representação da deusa Tanit, das quais o mais famoso exemplo, quase em tamanho real, vem do santuário Thinissut. O mesmo arquétipo iconográfico em relevo foi usado na decoração de basílicas cristãs, especialmente em relação a deusa-mãe. Dois exemplos, um da região de Bou Ficha, e um similar em Nabeul, mostram duas mulheres, cada uma com uma criança em seus joelhos e dois tronos. Objetos semelhantes foram ainda produzidos na oficina ARS de Oudhna durante o $6^{\circ}$ séc. EC, com moldes feitos em gesso (Bonifay, 2004, fig. 43).

As lâmpadas tardias em Sigillata Africana (tipo Atlante X) são filiadas à sigillata africana $C$ da Tunísia central (Hayes Tipo IIA) e à sigillata africana D do norte da Tunísia (tipo II B Hayes). Os produtos convencionais bem conhecidos (grupos C2 e C3) da Tunísia central são datados do $5^{\circ}$ ao início do $6^{\circ}$ séculos EC, cuja manufatura é atestada por uma oficina que operava em Sidi Marzouk Tounsi. As estratigrafias de Sidi Jdidi e Marselha mostram variantes dos tipos mencionados, com uma diversidade de decorações no disco do objeto que perpassam a mitológica (Aquiles e Heitor) e as cenas bíblicas (por exemplo, Adão e Eva, o sacrifício de Abraão). Também notam-se temas como o vigia da videira, animais, plantas, vasos, enfeites e formas geométricas abstratas, além de iconografias cristãs que incluem as representações de santos da igreja (Oudhna, grupo D2). Os sinais cristãos mais evidentes nessas lâmpadas são a cruz monogramática e o chi rho (que curiosamente parece mais nas lucernas norte-africanas do que nas palestinas). O exame das lucernas encontradas em Rougga demostra que a produção de lâmpadas de óleo em Bizacena não se limitou temporalmente aos $5^{\circ}-6^{\circ}$ séculos EC, mas esteve atuante durante o $6^{\circ}-7^{\circ}$ séculos EC, produzindo tipos alterados a partir dos modelos considerados "clássicos". A continuidade de temas, transmissão da informação e a forma como foram incorporados os padrões decorativos, torna evidente que os artesãos norte-africanos imitavam outras mercadorias (por exemplo, formas Hayes 82-85, 90-105), inspirados em temas e signos do Oriente Médio.

O norte da África realmente tornou-se romano, no que concerne à produção cerâmica, apenas durante o $2^{\circ}$ séc. EC. Durante a Antiguidade, a tradição romana foi, em certa medida, mais vibrante na África do que em muitas outras regiões do Mediterrâneo Antigo. As conhecidas oficinas de ARS atualmente podem ser reconhecidas através da pesquisas arqueológicas para as regiões de el Mahine, Oudhna, e Sidi Marzouk Tounsi. Todas essas oficinas são tardias e têm a mesma datação. A perspectiva comparativa sugere que as formas mais comuns não mudaram desde o séc. $4^{\circ}$ ao $7^{\circ} \mathrm{EC}$. O período entre o $5^{\circ}$ e $7^{\circ}$ séculos EC foi o apogeu de fabricação da lucernas africanas de verniz vermelho 
(ARS), lembrando formas anteriores de tipos imperiais. A substituição de importação sugere técnicas de produção, envolvendo os mesmos moldes de gesso, embora a decoração relativa a deuses e deusas tenha sido em certa medida substituída por cruzes (Bonifay 2007: 147-50). Todavia, as figurações de animais foram representação constantes nas lucernas da região.

A influência do Mediterrâneo Oriental pode ser atestada também nas lucernas torneadas, denominadas "vândalas", em camadas bizantinas. A evidência demonstra que a maioria das lucernas descobertas em Cartago deriva de níveis bizantinos (Bonifay 2004: 429). Um fenômeno também aparente na estratigrafia de Cartago é que as lucernas moldadas sobreviveram até o $5^{\circ}$ séc. EC. Já os modelos tardo-antigos permaneceram em uso até o início do $6^{\circ}$ século EC. Parece bastante razoável supor que essas lucernas tornaram-se acessíveis através da rede de inter-fluxo entre a zona costeira do norte da África (Cartago), a zona costeira da Fenícia (Tiro) e a zona costeira da Palestina (Cesareia Marítima, Apollonia, Yafo, Ascalão, Gaza), principalmente. Os temas iconográficos das lucernas africanas de Terra Sigillata derivaram de uma variedade de lâmpadas moldadas que se espalharam amplamente em toda a região das províncias da Syria e Palaestina a partir do $3^{\circ}$ EC (Orssaud e Sodini, 1997: 6364; Tal e Teixeira Bastos, 2015: 345-368).

A mudança da indústria cerâmica para o centro da cidade é um fenômeno bizantino bem conhecido. No decorrer do $3^{\circ}$ e $4^{\circ}$ sécs. EC, a indústria de ARS parece ter sido intimamente ligada a grandes propriedades rurais e as oficinas ARS ligadas à área de cidades foram, consequentemente, consideradas um desenvolvimento posterior, exatamente devido a produção de ânforas e de cerâmica de armazenamento. O final do $5^{\circ}$ ou o início do $6^{\circ}$ sécs. EC, antes da conquista bizantina, parece ter marcado um retorno à situação anterior, e as oficinas do norte prosperaram mais uma vez. As oficinas mais importantes do período não mais foram situadas no Mejerda (El Mahrine), mas no vale Oued Miliane (Oudhna) e Cartago (Mackensen e Schneider, 2002, 2006). Oficinas em torno desta cidade foram aparentemente as últimas a produzir e exportar ARS até o final do $7^{\circ}$ ou início do $8^{\circ}$ sécs. EC.

O deslocamento da produção norte-africana para o centro de Bizacena na segunda metade do $5^{\circ} \mathrm{EC}$ também pode ser ligado a circunstâncias políticas e perseguição religiosa cristã sob a nova classe dominante no território vândalo. A presença de judeus no norte da África para além da cultura material, é frequentemente atestada pela antiga polêmica literária cristã e rabínica. Coleções de lucernas decoradas com menorah, são particularmente associadas aos judeus da África do norte (Lund, 1995; Barbera e Petriaggi, 1993: 63, 88, 284, 285, fig. 66). A perspectiva é que os judeus exibiram uma gama de práticas culturais no norte da África que excedem as afirmações acadêmicas e taxonomias “ortodoxas" rabínicas atualmente vigente (Stern 2008: 305-309). 
A presença judaica em Cartago e em outros lugares na África é corroborada por inscrições que contêm nomes e adjetivos (Iudaeus) particularmente utilizados. A simbolização judaica permitiu que os estudiosos identificassem como grupos judeus enterramentos em Gammarth e Oea, e estelas funerárias isoladas por toda a África Proconsular, a Mauretânia e Tripolitânia também estão associadas a presença judaica no norte da África. Contudo, telhas funerárias, tigelas, e lucernas, retratam cenas bíblicas e figuras das representações de Jonas, Adão e Eva, sugerem que estes símbolos foram manipulados quer por judeus ou por cristãos. Entretanto, é notável, como sugerido por Stern (2008: 306), o questionamento que "objetos com figuração bíblica que não possuem explicitamente marcadores 'judaicos' deveriam necessariamente ser rotuladas como 'cristãos'? Podem palavras usadas em um epitáfio emular simultaneamente noções cristãs e judias sobre a vida após a morte?". Cabe salientar, novamente, que os judeus do norte da África romana viviam em ambientes culturais profundamente complexos e sua evidência material reflete este aspecto.

Como aconteceu na Palestina Romana, judeus deram a seus filhos nomes populares locais, usaram o latim vernacular para comemorar os seus mortos e construíam seus cemitérios de acordo com o costume local africano. Assim, em muitos casos, os judeus norte-africanos e/ ou judeus-berberes marcavam-se de forma semelhante aos seus vizinhos materialmente, ao mesmo passo que mantiveram relações de conectividade nas redes judaicas do Mediterrâneo Antigo, especialmente na Palaestina, renovadas nos $3^{\circ}-4^{\circ}$ séculos EC pela dispersão dos judeus e as emergentes redes de contatos. As lucernas de Terra Sigillata da África Proconsular e os corpus arqueológico remanescente apresentado sustentam essas possibilidades. As identidades dos judeus no norte da África foram complexas, com identificações culturais que variavam e demonstram pela materialidade aceitar relação inter-pessoais e relações entre-grupos no Orbis Romanorum. A emergência de redes de distribuição cerâmica no Mediterrâneo Antigo teve um papel fundamental durante esse processo de afiliação religiosa e formação das identidades sociais-culturais.

\section{Bibliografia}

AHUJA, R.K.; MAGNANTI, T. L.; ORLIN, J.B. Network Flows: Theory, Algorithms, and Applications. New Jersey: Pearson Education Inc., Prentice Hall, Englewood Cliffs, 1993.

AHUJA, R.K.; LIU, J.; ORLIN, J.B.; GOODSTEIN, J.; MUKHERJEE, A. 2004. A neighborhood search algorithm for the combined through fleet assignment model with time window. Amsterdã: Social Networks 44: 160-171. 
BANG, P. F. The Roman Bazaar: A Comparative Study of Trade and Markets in aTributary Empire. Cambridge: Cambridge University Press, 2008.

BARBERA, M.; PETRIAGGI, R. Museo Nazionale Romano - Le Lucerne Tard-Antiche di produzione Africana. Roma: Istituto Poligrafico e Zecca dello Stato, 1993.

BES, P. Once upon a time in the East. The chronological and geographical distribution of Terra Sigillata and Red Slip Ware in the Roman East. Roman and Late Antique Mediterranean Pottery 6. Oxford: Archaeopress, 2015.

BES, P.; POBLOME, J. (Not) See the wood for the trees? 19.700+ sherds of Sigillata and What we can do with them. Rei Cretariae Romanae Acta 40, 2007, 1-10.

BES, P.; POBLOME, J. African Red Slip Ware on the move: the effects of Bonifay's Études for the Roman East. In: HUMPHREY, J.H. Studies on Roman pottery of the provinces of Africa Proconsularis and Byzacena (Tunisia): homage à Michael Bonifay. Rhode Island: Journal of Roman Archaeology, 2009.

BONIFAY, Michel. Études sur la céramiqueromaine tardive d'Afrique, BAE Int. Ser. 1301. Oxford: Archaeopress, 2004.

BONIFAY, M. Observations sur la diffusion des Céramiques Africaines en Méditerranée Orientale durant L'Antiquité Tardive. Paris: Mélanges Jean-Pierre Sodini, Travaux et Mémoires 15, 2005a, 565-581.

BONIFAY, M. Observations sur la typologie des lampes africaines (IIe - VIIe siècle). In: CHRZANOVSKI, L. (ed). Lychnological Acts 1. Actes du 1er Congrès international d'études sur le luminaire antique. Montagnac: Éditions Monique Mergoil, 2005b.

BONIFAY, M. Ceramic Production in Africa during Late Antiquity: Continuity and Change. In: LAVAN, L.; ZANINI, E.; SARANTIS, A. (ed). Technology in Transition A.D. 300-650. Late Antique Archaeology 4, 2007,143-158.

BONIFAY, M. Africa: Patterns of consumption in coastal regions versus inland regions. The ceramic evidence (300-700 A.D.). In: LAVAN, L. (ed). Local Economies? Production and Exchange of Inland Regions in Late Antiquity. Late Antique Archaeology 10, 2013, 529-566.

BRANDES, U.; ROBINS, G.; MCCRAINE, A.; WASSERMAN, S. What is network science? Cambridge: Network Science 1 (01), 2013,1-15.

BRUGHMANS, T. The roots and shoots of archaeological network analysis: a citation analysis and review of the archaeological use of formal network methods. Cambridge: Archaeological Review from Cambridge 29 (1), 2014, 18-41. 
BRUGHMANS, T; COLLAR, A; COWARD, F. Introduction: challenging network perspectives on the past. In: BRUGHMANS, T; COLLAR, A; COWARD, F (Eds.) The connected past: challenges to network studies of the past. Oxford: Oxford University Press, 2015.

BRUGHMANS, T.; POBLOME, J. Roman bazaar or market economy? Explaining tableware distributions through computational modeling. Cambridge: Antiquity 90, 2016, 393-408.

BUSSIÈRE, J. Nouveaux outils de potiers africains d'époque romaine (IVe Vie S.). Pisa, Roma: Facta 2, A Journal of Roman Material Culture Studie, 2008.

BUSSIÈRE, J. Production et circulation des lampes tardives d'Algerie. In: CHRZANOVSKI, L. Le Luminaire antique, Lychnological Acts 3. Montagnac: Éditions Monique Mergoil, 2012.

CAPELLI, C.; BONIFAY, M. Archéométrie et Archéologie des céramiques africaines: une approche pluridisciplinaire, 2. Nouvelles Donnes sur la céramique culinaire et les amphores. In: POULOU-PAPADIMITRIOU, et al.; LRCW 4 Late Roman Coarse Wares, Cooking Wares and Amphorae in the Mediterranean: Archaeology and archaeometry, The Mediterranean: a market without frontiers. BAR International Series 2616 (I) 2014.

CARRIGNON, S., MONTANIER, J-M., RUBIO-CAMPILLO, X. Modelling the Co-evolution of Trade and Culture in Past Societies. Huntington Beach, CA: Proceedings of the 2015 Winter Simulation Conference, 2015, 3949-3960.

COLLAR, A. C. F. Network theory and religious innovation. Tel Aviv.: Mediterranean Historical Review 22(1), 2007, 149-162.

COLLAR, A. C. F. Religious networks in the Roman Empire: The spread of new ideas. Cambridge: Cambridge University Press, 2013a.

COLLAR, A. C. F. Re-thinking Jewish ethnicity through social network analysis. In: KNAPPET, C. (ed) Network analysis in archaeology: New approaches to regional interaction. Oxford: Oxford University Press, 2013b, 223-246.

COLLAR, A.; COWARD, F.; BRUGHMANS, T.; MILLS, B. J. Network in Archaeology: Phenomena, Abstraction, Representation. Nova York: Journal of Archaeological Method and Theory 22, 2015, 1-32.

COLLINS, J.J. Between Athens and Jerusalem. New York. The Crossroad Publishing Company, 1986.

DENEUVE, J. Lampes de Carthage. Paris, 1969. 
DENEUVE, J. Céramiques et lampes africaines sur le côte de Provence". AntAfr 6, 1972, 219-240.

DENEUVE, J. Note sur quelques lampes africaines du IIIe siècle. AntAfr 22, 1986, 141-161.

FOUCAULT, M. Microfísica do poder. São Paulo: Graal, ed 23, 2007.

FLEMING, M.I. D’A., TEIXEIRA-BASTOS, M., PORTO, V.C. Arqueologia Clássica e as Humanidades Digitais no Brasil. Pelotas: Cadernos do LEPARQ, vol. XIV, n' 27, 2017, 11-28.

FLEMING, M.I.D'A. Lucernas Norte-Africanas Tardias de Terra Sigillata: Curadoria de Coleções Museológicas e Pesquisas Arqueológicas. Unifesp, São Paulo: Heródoto, v.3, 2018, 431-445.

GOODMAN, M. Mission and Conversion: Proselytizing in the Religious History of the Roman Empire. Oxford: Clarendon Press, 1994.

GUÉRY, R. Les marques de potiers sur terra sigillata découvertes en Algérie. I. Sigillées provinciales (hispanique et gallo-romain). AntAfr 13, 1979, 23-98.

GUÉRY, R. Les marque de potiers sur Terra Sigillata découvertes en Algérie. II. Sigillée tardo-italique. AntAfr 23 (1), 1987, 49-192.

HAYES, J.W. Late Roman pottery. London: British School at Rome, 1972.

HAYES, J.W. Lamps. In: STIRLING, L.M.; MATTINGLY, D.J., BEN LAZREG, N. Leptiminus (Lamta), report no. 2. The East Baths, cemeteries, kilns, Venus mosaic, site museum, and other studies. JRA Suppl. 41, 2001, 202-205.

HESLIN, K. Emerging Markets: Import Replacement in Roman North Africa. Bollettino di Archeologia On Line, 2008, 54-66.

ISAKEN, L. "O what a tangled web we weave" - Towards a practice that does not deceive. In: KNAPPET, C. (Ed.) Network analysis in archaeology: New approaches to regional interaction. Oxford: Oxford University Press, 2013, 43-70.

LATOUR, B. Reassembling the Social. An introduction to Actor-Network-Theory, Clarendon Lectures in Management Studies. Oxford: Oxford University Press, 2005.

LAPP, E.C. Marketing Religious Difference in Late Antique Syria-Palestine: Clay Oil Lamps as Clientele Indicators. In: EDWARDS, R.; MCCULLOUGH, C. T. (eds.) The Archaeology of Difference. Gender, Ethnicity, Class, and the 
"Other" in Antiquity: Studies in Honor of Eric. M. Meyers. Boston: Annual of the American Schools of Oriental Research 60/61. 2006, 371-380.

LEWIT, T. Dynamics of fine ware production and trade: the puzzle of supra-regional exporters. Journal of Roman Archaeology 24, 2011, 313-333.

LUND, J. A Synagogue at Carthage? Menorah-lamps from the Danish Excavations. JRA 8, 1995, 245-262.

MACKENSEN. M. Die spätantiken Sigillata - und Lampentöpfereien von el Mahrine (Nordtunisien): Studien zur nordafrikanischen Feinkeramik des 4. Bis 7. Jahrhunderts / mit ein Beitrag von Sebastian Stortz. München: C.H. Beck'sche Verlagsbuchhandlung, 1985. Apud Barbera e Petriaggi, 1993, 425.

MACKENSEN. M.; SCHNEIDER, G. Production Centres of African Red Slip Ware (3rd- 7th c.) in Northern and Central Tunisia: Archaeological Provenance and Reference Groups Based on Chemical Analysis. Journal of Roman Archaeology 15, 2002, 121-158.

MACKENSEN. M.; SCHNEIDER, G. Production Centres of African Red Slip Ware (2nd-3rd c.) in Northern and Central Tunisia: Archaeological Provenance and Reference Groups Based on Chemical Analysis. Journal of Roman Archaeology 19, 2006, 163-190

MANN, M. The Sources of Social Power. Volume 1. A History of power from the beginning to A.D. 1760. Cambridge: Cambridge University Press, 1986.

NEWMAN, M. E. Networks: an introduction M. E. Newman, Oxford: Oxford University Press, 2010.

KNAPPET, C. An archaeology of interaction: Network perspectives on material culture and society. Oxford: Oxford University Press, 2011.

KNAPPET, C. Network analysis in archaeology: New approaches to regional interaction. Oxford: Oxford University Press, 2013.

ORSSAUDE, D.; SODINI, J.-P. Leas lampes tournées de Qal'at Sem'an et leurs parallèles dans le bassin méditerranéen. La Céramique médiévale en Méditerranée. Aix-en-Provence, 1997, 63-72.

PEEPLES, M. A.; MILLS, B. J.; ROBERTS, J. M.; CLARK, J. J.; HAAS, W. R., Jr. Analytical issues in the application of network analyses to archaeology. In: BRUGHMANS, T; COLLAR, A; COWARD, F (Eds.) The connected past: Challenges to network studies of the past. Oxford: Oxford University Press, 2014. 
RAMALHO, J. Eusebio e Constantino. O início de uma Igreja Imperialista. São Paulo: Fonte

Editorial, 2013.

REMESAL RODRÍGUEZ, J. La annona militaris y la exportación de aceite bético a Germania. Madrid: Universidad Complutense, 1986.

REMESAL RODRÍGUEZ, J. 'Promoción social en el mundo romano a través del comercio'. In: SIMÓN, M.; POLO, P.; REMESAL, R. (eds) Vivir en tierra extraña: Emigración e integración cultural en el mundo antiguo. Barcelona: Instrumenta 16, 2004, 125-36.

REYNOLDS, P. "Trade networks of the East, 3rd to 7th centuries: the view from Beirut (Lebanon) and Butrint (Albania)(fine wares, amphorae and kitchen wares). In: MENCHELLIM, S.; SANTORO, S.; PASQUINUCCI, M.; GUIDUCCI, G (eds). LRCW3. Late Roman coarse wares, cooking wares and amphorae in the Mediterranean. Oxford: BAR S2185, 2010.

SCHEIDEL, W. Quantifying the Sources of Slaves in the Early Roman Empire. Journal of Roman Studies 87, 1997, 156-69.

SCHEIDEL, W., and von Reden S. (eds). The Ancient Economy. Edinburgh: Edinburgh University Press, 2002.

SCHEIDEL, W.; MORRIS, I.; SALLER, R.(eds). The Cambridge Economic History of the Greco-Roman World. Cambridge: Cambridge University Press, 2007.

SCOTT, J.; CARRINGTON, P. J. (eds.), The SAGE handbook of social network analysis. Los Angeles: SAGE, 2011.

STARK, R. The Rise of Christianity. A sociologist reconsiders history. Princeton N.J.: Princeton University Press, 1996.

STERN, K. B. Inscribing Devotion and Death. Archaeological Evidence for Jewish Populations of North Africa. Leiden/Boston: Brill, 2008.

TAYLOR, K. Brainwashing. The Science of Thought Control. Oxford: University Press, 2004.

TAL, O., TEIXEIRA-BASTOS, M. More on the Intentionally Broken Discus Lamps from Roman Palestine: Mutilation and Its Symbolic Meaning. In: BLÖMER, M.; LICHTENBERGER, A.; RAJA, R. (eds) Religious Identities in the Levant from Alexander to Muhammed: Continuity and Change. Contextualizing the Sacred 4. Turhout: Brepols, 2015, 345-368. 
TEMIN, P. 'A Market Economy in the Early Roman Empire'. Journal of Roman Studies 91, 2001, 169-81.

TEMINA, P. The Roman market economy. Princeton (NJ): Princeton University Press, 2014.

TCHERNIA, A. The Romans and Trade. Oxford: Oxford University Press, 2016.

WASSERMAN, S.; FAUST, K. Social network analysis: methods and applications. Cambridge: Cambridge University Press, 1994.

WICKAHM, C. Framing the Early Middle Ages: Europe and the Mediterranean, 400-800. Oxford: Oxford University Press, 2005.

WOOLF, G. Only connect? Network analysis and religious change in the Roman World. Hélade, v. 2, n. 2, 2016, 43-58. 